\title{
Libro: El peronismo vuelve a enamorar. La articulación de un imaginario político durante el gobierno de Menem
}

Gastón Souroujon

HomoSapiens, Rosario, 2014 (273 pp.)

\section{Federico Zingerling von der Thüsen}

Licenciado en Ciencia Política por la Universidad Nacional del Litoral, Argentina.

E-mail: fzingerling@unl.edu.ar

En este libro, Gastón Souroujon analiza la metamorfosis de Carlos Menem desde su acceso al poder en 1989 hasta su partida, diez años después. Dicha transformación implicó la concreción de un programa de gobierno orientado hacia la desregulación, privatización, reforma del Estado y acercamiento a los Estados Unidos, el cual se encontraba en las antípodas de lo que se había prometido en campaña y de las políticas nacionalistas e industrialistas del primer peronismo.

En los primeros años de la década del noventa se produjo una prolífera literatura que analizó cómo la gestión de Menem logró aplicar políticas resistidas en años anteriores, contar con un apoyo social contundente a la hora de la profundización de dichas medidas y no fracasar en la primera prueba electoral de su primer mandato ni en las siguientes. Frente a estos trabajos, centrados en los primeros años del gobierno de Menem, Souroujon plantea una visión global de los gobiernos menemistas y, a su vez, propone un corrimiento de las herramientas epistemológicas de la teoría de la elección racional. Distintas explicaciones han dado los académicos en un intento de descifrar la "anomalía" del menemismo a partir de estas herramientas. Algunos han puesto el énfasis en la predisposición a tomar riesgos que las situaciones de crisis, como la hiperinflación, generaron, mientras que otros enfatizaron la predisposición de la sociedad latinoamericana a aceptar la política de libre mercado, valorando la estabilidad económica y teniendo una mayor estima a la disminución de los índices inflacionarios en detrimento del aumento del empleo o la producción.

Souroujon critica la reducción racionalista e individualista y busca, en cambio, enfatizar el papel que posee la esfera de lo imaginario para interpretar los fenómenos políticos. De este modo, busca demostrar que la legitimidad e identidad de todo gobierno, así como la posibilidad de dotar de significación a toda experiencia política, se sustenta en la capacidad de la clase política de articular un imaginario político. Los elementos del imaginario de la democracia liberal de fines del siglo $\mathrm{XX}$ son analizados, así, como los reelaborados y resignificados por el menemismo en su intento de articular una identidad propia y dotar de legitimidad a su proceso 
de reforma y a su gobierno en general. Esta tarea plantea -en los capítulos segundo al quinto- cuatro grandes construcciones imaginarias: el trabajo sobre la tradición imaginaria, la relación carismática, el mito político y las ideas fuerzas. Las fuentes que analiza son los discursos del propio Menem y los de sus partidarios, tanto en actos públicos, declaraciones informales o en sus apariciones televisivas.

En el primer capítulo, Souroujon señala que existen dos tipos de lecturas en relación al imaginario político peronista. En primer lugar, ubica a la teoría del "peronismo de dos caras", que plantea una divergencia entre los motivos por los cuales los sectores populares y los medios altos brindarían apoyo al gobierno de Menem: los unos por la vigencia de un imaginario peronista "original" y los otros por sus medidas de estabilización económicas (Sidicaro, 2002). En segundo lugar, coloca a las ideas de Levitsky (2005), que destacan la supervivencia en los estratos populares de un núcleo duro del imaginario peronista tradicional, mientras que los sectores elevados se regían por conductas estratégicas. Souroujon, aquí, indica que ambas lecturas parten del supuesto de que el comportamiento guiado por emociones e imaginarios es sólo de los grupos populares, y los sectores de mayores ingresos y educación se "desprenden" de él y guían su accionar "racionalmente". Esto significaría que los imaginarios se vinculan únicamente con el ámbito de la carencia, ya que la pobreza y la falta de educación serían las causas de un comportamiento no instrumental (p. 34). Por otro lado, estos planteamientos sobredimensionan la vigencia, en las clases populares, de ese imaginario peronista tradicional que sólo necesitaría de un sujeto como Menem para ser reactivado.

Souroujon, a su vez, se pregunta qué fue lo que permitió el éxito de los mitos políticos articulados por el menemismo, siendo que otros no lo lograron. Parafraseando a Milibrath (1968), plantea que la inclinación a creer está signada fuertemente por la valoración particular que tenemos de esa creencia. En los momentos de crisis, las construcciones imaginarias gestadas para dar respuesta a sentimientos de caos e incertidumbre constituyen fuertes lazos de creencia. Así, sostiene Souroujon, el sorteamiento de la crisis hiperinflacionaria estableció una especie de contrato de fidelidad de la mayoría de los argentinos con el gobierno menemista.

En el capítulo dos, "Los espectros de Perón", se analiza la reaparición y transformación del imaginario peronista tradicional. Souroujon analiza cómo el menemismo se reapropió, silenció y resignificó el imaginario peronista buscando forjar el suyo propio. Señala que las continuidades entre el general Perón y Menem -dos líderes carismáticos con capacidad de movilización- exceden a ambos personajes, ya que son parte de la lógica democrática.

El análisis de los discursos de Menem, acompañados por una cuantiosa cantidad de citas y referencias que ayudan a comprender el período, presenta una gran riqueza. Se indagan los usos de Perón por parte de Menem, hallando una etapa de estabilidad donde las mismas estrategias argumentativas son utilizadas, buscando revivir el carisma de Perón la figura de Menem, a la vez que se intenta presentar este resurgimiento como legítimo dentro del peronismo. Luego Souroujon halla diferencias analíticas entre uno y otro que se resumen en la "reactualización doctrinaria", la "incorporación de Menem en la historia peronista" y en los "pa- 
ralelismos entre los acontecimientos que debió padecer Perón y los de la década del noventa". En segundo lugar observa fluctuaciones en la utilización que hace el menemismo de Perón, la cual varía según la coyuntura política y la relación de Menem con sus compañeros del justicialismo. Aquí, el autor identificó tres fases: a) desde 1989 a 1992, en donde se produce el intento de silenciar e invertir a Perón; b) desde 1993 a 1996, donde la figura de Perón retorna al folklore peronista tradicional; y c) desde 1997 a 1999, donde Menem realiza más paralelismos entre su gestión y la del General, evidenciando aún más la división peronistasantiperonistas.

En el tercer capítulo, se despliegan elementos para comprender la naturaleza de una relación de rasgos carismáticos entre el líder y sus seguidores y profundizar sobre la doble naturaleza de un caudillo y sus estrategias de representación. Dentro de este tipo de relación se introduce al populismo y cuál fue la estrategia populista inaugurada por el menemismo. Es así que la identificación entre la voluntad del pueblo y del líder no sólo se ratifica a través de las urnas, sino que también requiere una conexión interna que el líder debe saber explotar. Se plantea un recorrido sobre los años menemistas haciendo hincapié en las diversas estrategias utilizadas por este gobierno y especialmente por el propio Menem para seducir a la sociedad. Ellas son la "estrategia de la autenticidad" de ese vínculo, y la "estrategia de la biografía", para retomar los orígenes biográficos de Menem y presentarlos como elementos y valores que son necesarios en la figura de un líder, como por ejemplo su procedencia de una provincia del interior y su origen humilde. Además, se remarca aquí la idea de que si pudo llegar a la presidencia fue debido a cualidades "especiales" de las que otros carecen. Por otro lado, el autor se refiere a la "estrategia de la autoconfianza", en la que Menem debe investirse para concebirse a sí mismo como el elegido para realizar una gran tarea. Esto se evidencia cuando el riojano plantea "yo prometí que iba a ser presidente y aquí estoy". Por último, la "estrategia de definir y domar la crisis", es decir, cómo Menem presenta la crisis heredada al inicio de su mandato y cómo la utiliza como recurso a lo largo de sus años de gobierno.

En el capítulo cuarto, Souroujon analiza las dimensiones implícitas en "El mito político de Argentina país del primer mundo". La primera de ellas, la "narratividad", precisa que el mito imprima un sentido, que otorgue significación a la experiencia política menemista. Luego la "dramaticidad", es decir la capacidad del mito de impulsar la acción, y por último la "maleabilidad", referida a la capacidad de los mitos políticos de ir reconvirtiéndose en el tiempo. Souroujon señala que la utilización de la expresión "primer mundo" es una determinación relevante para la construcción imaginaria, dado que es la imagen que posibilita integrar en su seno a los tres mitemas (unidades constitutivas que se entrecruzan para dar vida al mito de Argentina país del primer mundo). Dichas mitemas son la "pacificación", el "protagonismo" y el "desarrollo". Sobre éstas se estructuró, a lo largo de los noventa, el relato del mito político; en estas mitemas se pueden observar modulaciones relacionadas con la coyuntura política que se van interrelacionando para conformar un relato común. 
En el último capítulo, "Las ideas fuerzas neoliberales", el autor plantea que existen ciertas construcciones imaginarias cuyas estructuras están fundadas sobre la base de teorías científicas, sean estas económicas, políticas o sociales, llamándolas "ideas fuerzas" (p. 179). Éstas, al igual que las otras construcciones imaginarias, son aceptadas por los sentimientos que despiertan y son reforzadas por el aspecto científico que presentan. El autor busca rastrear el proceso por el cual la teoría económica neoliberal fue presentada por la clase política menemista, y para ellos tiene en cuenta las estrategias argumentativas utilizadas para lograr consenso ante la sociedad. Además, intenta analizar a qué símbolos fueron asociadas las ideas fuerzas y cómo se articularon con el resto de las construcciones imaginarias. En primer lugar, el autor hace un pequeño análisis histórico descriptivo buscando indagar sobre las características de los principales actores responsables de difundir las ideas neoliberales en Argentina, los think tanks. Sobresale el papel de los "tecnopolíticos", es decir, expertos, generalmente economistas, que surgen de esos think tanks y se introducen en las áreas de decisión política. No obstante, aclara el autor, es importante recalcar que las ideas y políticas neoliberales (centradas en cuatro ejes: estado, mercado, democracia-libertad y moneda) no desembarcaron en la Argentina luego de la asunción de Menem.

Los discursos neoliberales en relación a estos cuatro ejes son analizados en detalle. Adjetivos como "dadivoso", "estafador", "prebendario" fueron utilizados entonces para describir la situación del Estado. Frente a ello, el Estado debía ser abordado de dos formas: por un lado, reducir su magnitud para administrarlo de forma eficaz y por otro, simplificar sus funciones para evitar que contribuya a nuevas crisis en el país. Refiriéndose al mercado, se hace hincapié en la llamada "teoría del derrame", a la que el menemismo recurrió para integrar la preocupación por la justicia social, ahora redefinida como símbolo de la competencia en el mercado, y la igualdad de oportunidades. A su vez, se intentó presentar las reformas pro-mercado como decisiones técnicas, rodeándolas de cientificidad, logrando una especie de legitimidad y blindaje hacia las críticas de sectores opositores, pregonando la veracidad del saber científico-económico. Además, estas medidas fueron presentadas como el único camino posible ante la crisis, eliminando el marco de disenso y de otras posibles acciones. Respecto a la democracia y libertad, el politólogo santafesino subraya que, según las premisas de los autores neoliberales de la época, ya no era el régimen político el que aseguraba la libertad, sino que eran los valores del mercado. Finalmente, es imposible hablar sobre la política monetaria en la década de los noventa sin pensar en las condiciones de hiperinflación y en la convertibilidad. Es por ello que en este segmento se podrán recorrer las concepciones del menemismo sobre el problema, cómo articuló su respuesta, cuáles fueron los elementos que eran considerados como dañinos al sistema y cómo debían ser eliminados. El dólar estadounidense cobrará importancia en estos aspectos, por lo cual el autor dedica un apartado a los usos del dólar, que, con o sin intención, remite a nuestra actualidad económica.

Para finalizar, la lectura del libro brinda una mirada innovadora para entender el periodo menemista, desligándose de los enfoques racionalistas que han "predo- 
minado". El trabajo muestra el rol central de la clase política como articuladora del imaginario político. Y sólo en este nivel de análisis del imaginario se puede comprender toda una década de acuerdo, por lo menos implícito, por parte de los gobernados con políticas fuertemente excluyentes. También a través de este análisis se puede comprender cómo el menemismo logró contruir poder en un contexto en el cual el rol de lo político estaba desacreditado y el Estado estaba siendo recortado en funciones y poderes.

\section{Bibliografía}

S. LEVITSKY (2005), La transformación del justicialismo. Del partido sindical al partido clientelista, 1982-1999, Buenos Aires, Siglo XXI.

L. MILIBRATH (1968), "The Nature of Political Belief and the Relationship of the Individual to the Government”, en American Behavioral Scientist, $\mathrm{N}^{\circ} 12$.

R. SIDICARO (2002), Los tres peronismos. Estado y poder económico. 1945-55/ 1973-73/ 1989-99, Buenos Aires, Siglo XXI. 